\title{
산개성단 M50 영역의 변광성 VARIABLE STARS IN THE REGION OF AN OPEN CLUSTER M50
}

\author{
전영범 \\ 한국천문연구원 \\ YOUNG-BEOM JEON \\ Korea Astronomy and Space Science Institute \\ E-mail: ybjeon@kasi.re.kr \\ (Received October 29, 2008; Accepted November 19, 2008)
}

\begin{abstract}
From the short-period variability survey (SPVS), we obtained time-series $B V$ CCD images in the region of an open cluster M50 (NGC 2323) for 10 nights from 2008 February 9 to 27. The observation was performed using a small refracting telescope $(\phi=155 \mathrm{~mm}, f=1050 \mathrm{~mm})$ in Bohyunsan Optical Astronomy Observatory (BOAO). M50 is included in the observing field of ASAS (The All Sky Automated Survey). In the region of M50, we found 8 new variable stars including two $\delta$ Scuti stars with short-periods and very small amplitudes. There are known nine variable stars by the catalogues of ASAS and GCVS in the region. We confirmed the variability of the known variable stars for six and non-variability for three.
\end{abstract}

Key words: clusters: - M50; NGC 2323, stars: variables $-\delta$ Scuti; Eclipsing binaries

\section{1. 서론}

보현산천문대의 단주기 변광성 탐사연구(SPVS; Jeon et al. 2005a)는 그동안의 시험관측을 통하여 $V=9$ 에서 14 등급 사이의 단주기변광성, 특히 $\delta$ Scuti 형 변광성의 탐사에 유용함을 확인하였다 (Jeon et al. 2004a, 2004b, $2005 \mathrm{~b}, 2007)$. SPVS는 우리 은하의 산개성단에 대한 단주기 변광성을 체계적으로 탐사하는데 주된 목적을 두 고 있다.

산개성단 $\mathrm{M} 50$ (NGC 2323)은 적경 $7^{h} 02^{m} \quad 42^{s}$, 적 위 $-8^{\circ} 23^{\prime}$ 으로서 은하면 $\left(b=-1^{\circ} \quad 18^{\prime}\right)$ 에 놓여있 다 $\left(\mathrm{WEBDA}^{1}\right)$. 이 성단은 비교적 밝고, 넓은 영역에 분 포하여 작은 구경으로 넓게 관측하는 SPVS의 좋은 관 측대상 중 하나이다. Clariá et al. (1998)에 따르면 거 리 $940 \mathrm{pc}$ 에 나이가 1 억년이며, Kalirai et al. (2003)은 거리 $1 \mathrm{kpc}$, 나이 1.3 억년의 결과를 구하였다. M50 영역 은 ASAS (The All Sky Automated Survey ${ }^{2}$. Pojmanski et al. 2005)의 관측 영역에 속하여 이미 변광성 탐사 가 이루어져 있으므로 우리의 관측 결과와 비교할 수 있 는 좋은 예가 될 것이다. $\mathrm{ASAS}$ 는 관측 가능한 변광성의 등급영역이 우리의 SPVS와 비슷하며, 각각의 관측영역

\footnotetext{
${ }^{1}$ http://www.univie.ac.at/webda/

${ }^{2}$ http://www.astrouw.edu.pl/asas/
}

을 2-3일에 한 번씩, 길게는 10 여년에 걸쳐 장기간 관 측이 이루어져서 긴주기의 변광성 탐사에 아주 효율적이 다. 하지만 관측회수가 제한되어 진폭도 작고 주기도 짧 은 $\delta$ Scuti형 변광성과 같은 단주기 변광성의 탐사에는 어려움이 있다. Rucinski (2007)에 따르면 ASAS의 경 우 관측된 변광성의 짧은쪽 주기는 대략 0.22 일 정도이 며, $\mathrm{W} \mathrm{UMa형} \mathrm{변광성이다.} \mathrm{반면에,} \mathrm{SPVS의} \mathrm{경우} \mathrm{하나}$ 의 관측영역에 대해 10 일 이상 지속적인 관측을 수행하 여 훨씬 짧고 $(\mathrm{P} \leq 0.05$ 일 $)$, 작은 변광진폭(Amplitude $\leq 0.012$ 등급)을 가진 변광성을 찾아낼 수 있다(Jeon et al. 2007). $\mathrm{ASAS}$ 의 결과 이외에는 산개성단 $\mathrm{M} 50$ 에 대 한 변광성탐사가 체계적으로 이루어진 예는 없다.

2 절에서는 관측 및 분석을 정리하였고, 3 절에 그 결 과를, 그리고 마지막 절에 전체결과의 요약 및 검토가 이루어졌다.

\section{2. 관측 및 분석}

그림 1 은 $V$ 영상 중 하나이며, 8 개의 새로 발견한 변광 성 (V1부터 $\mathrm{V} 8$ 까지)과 6개의 알려진 변광성 및 이 영역 에서 알려진 $\mathrm{GCVS}^{3}$ (Samus et al. 2004) 변광성 등, 관

\footnotetext{
${ }^{3}$ http://www.sai.msu.su/groups/cluster/gcvs/gcvs/
} 


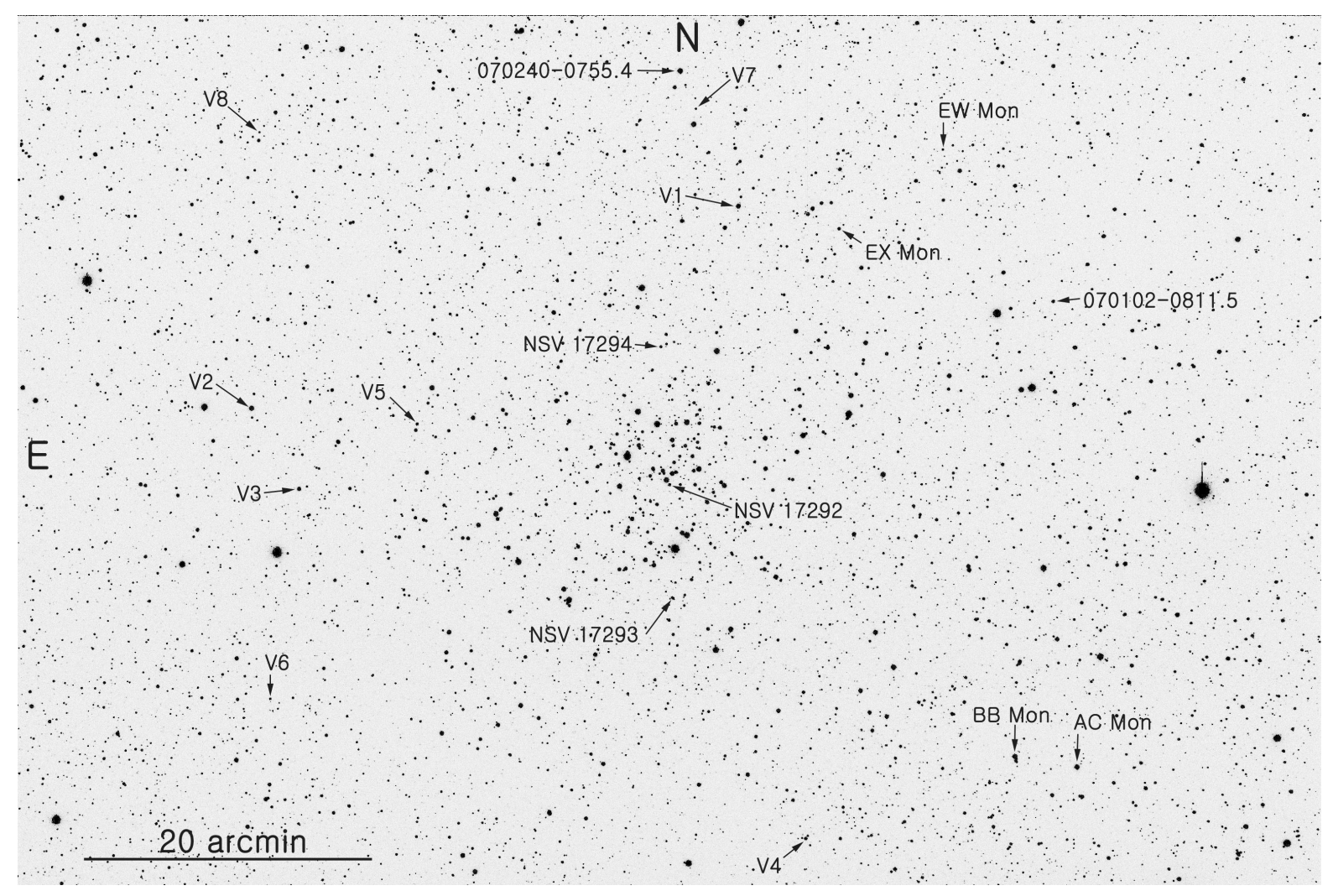

그림 1.- M50 영역에서 관측된 변광성의 분포도.

측된 모든 변광성을 나타내었다. 이 영역에 대한 관측은 2008 년 2 월 9 일부터 2 월 27 일 사이에 $V$ 필터로 10 일간, $B$ 필터로 9 일간 이루어졌다. 노출시간은 각각 200 초이 다. 관측에 사용된 망원경은 구경 $155 \mathrm{~mm}$ 의 소형 굴절 망원경이며, $2048 \times 3072$ 소자를 가지고 있는 $\mathrm{CCD}$ 카 메라가 사용되어 전체 관측영역은 $1.0^{\circ} \times 1.5^{\circ}$ 이다. 관 측 시스템에 대한 자세한 설명은 Jeon et al. (2005a, 2007)에 수록되었다.

관측된 $\mathrm{CCD}$ 영상자료는 $\mathrm{IRAF/CCDRED} \mathrm{(Stetson}$ 1987, Massey \& Davis 1992)를 이용하여 영점보정, 암 잡음보정, 플랫보정의 전처리 과정을 수행하였으며, 이 과정과 측광 과정은 이전의 연구와 같다 (Jeon et al. $2005 \mathrm{~b}, 2007)$. 단지 자동추적장치 $(\mathrm{AGU})$ 의 원활한 작동 으로 노출시간을 150 초에서 200 초로 증가시켰다.

이 영역에서 찾아진 별은 모두 6,000 여개이며, 이들 모두에 대해 각각의 기준별을 설정하여 차등등급을 구 하여 광도곡선을 컴퓨터 화면에 하나씩 띄워서 육안으 로 변광 여부를 확인하였다. 각각의 기준별은 약 200 여 개의 포화되지 않은 밝은 별 중에서 가장 가까이 위치한 별을 골라서 사용하였다. 기준별 중에서 변광성이 검출 되면 이들을 제외한 후 다시 비교성을 고르고, 이 과정 을 반복하여 최종적인 차등측광을 수행하였다.
3. 결과

$\mathrm{M} 50$ 을 중심으로한 $1.0^{\circ} \times 1.5^{\circ}$ 영역에서 측광이 이루 어진 6,000 여개의 별 중에서 모두 14 개의 변광성을 찾았 다. 이들 중 8 개는 새로운 변광성이며, 6 개는 알려진 변 광성이다. 표 1 은 $\mathrm{M} 50$ 영역에서 관측된 변광성에 관한 결과를 나타낸 것이다.

표 1 에서 별의 이름은 새로 발견한 변광성에 대해 $\mathrm{V} 1$ 부터 V8까지 부여하고, 기존의 알려진 변광성은 전 통적인 변광성 이름을 우선적으로 기재한 후 $\mathrm{ASAS}$ 의 이름을 같이 수록하였다. ID는 $2 \mathrm{MASS}$ 와 USNOB1.0의 것이며, 등급과 색은 Clariá et al. (1998)의 결 과를 이용하여 표준화한 것이다. 그 뒤로 관측으로부터 얻어진 Epoch, 주기, 변광진폭 및 변광성 분류를 나타 내었다. 변광성 분류는 $\mathrm{GCVS}$ 의 분류법을 따랐다. $\mathrm{L}$ 은 느리게 변하는 불규칙 변광성이며, 그 중에서 만기형은 $\mathrm{LB}$ 로 분류된다.

관측된 변광성 14 개 중에서 2 개는 새로운 $\delta \mathrm{Scuti}$ 형 변광성이며, 식변광성 4 개, $\delta$ Cepheid 1 개, RR Lyrae 변 광성으로 추정되는 것 1 개 그리고 나머지 6 개의 변광형 태를 알 수 없는 것 등이 포함되었다. 기존에 알려진 변 광성은 $\mathrm{GCVS}$ 와 $\mathrm{ASAS}$ 에 수록된 것이다. M50 영역은 $\mathrm{ASAS}$ 에서 약 8 년 동안 관측이 수행된 영역인데 이번 
표 1.- M50 영역에서 관측된 변광성의 물리량.

\begin{tabular}{|c|c|c|c|c|c|c|c|c|}
\hline \multirow[t]{2}{*}{ Name } & \multicolumn{2}{|l|}{ ID } & \multirow[t]{2}{*}{$<V>$} & \multirow[t]{2}{*}{$<B>-<V>$} & \multirow{2}{*}{$\begin{array}{c}\text { Epoch } \\
(\text { HJD2450000+) }\end{array}$} & \multirow{2}{*}{$\begin{array}{c}\text { Period } \\
\text { (day) }\end{array}$} & \multirow{2}{*}{$\begin{array}{l}\text { V Amplitude } \\
\text { (mag) }\end{array}$} & \multirow[t]{2}{*}{ Type } \\
\hline & 2MASS & USNO-B1.0 & & & & & & \\
\hline V1 & $07022606-0804294$ & 0819-0135962 & 10.07 & 0.48 & - & - & - & $\mathrm{L}$ \\
\hline $\mathrm{V} 2$ & 07043886-0816501 & 0817-0131511 & 9.91 & 1.73 & - & - & - & LB \\
\hline V3 & $07042681-0822186$ & 0816-0127043 & 10.69 & 0.40 & 4506.965 & 0.2281 & 0.03 & DSCT \\
\hline V4 & $07021352-0846426$ & 0812-0118885 & 12.35 & 0.38 & 4505.946 & 0.0398 & 0.04 & DSCT \\
\hline V5 & $07035447-0818160$ & 0816-0126553 & 12.56 & 1.81 & - & - & - & LB \\
\hline V6 & 07043649-0836120 & 0813-0122216 & 12.60 & 1.59 & 4509.053 & 0.7614 & 0.57 & EW \\
\hline V7 & $07023663-0757556$ & 0820-0140677 & 13.70 & 0.20 & 4524.036 & 1.8658 & 0.35 & $\mathrm{EA}$ \\
\hline V8 & $07043416-0758304$ & 0820-0142730 & 14.30 & 0.87 & 4507.410 & 0.5087 & 0.25 & $\mathrm{RR} ?$ \\
\hline $070240-0755.4^{a}$ & $07024051-0755220$ & 0820-0140746 & 9.49 & 1.73 & $1995.1^{a}$ & $59.01^{a}$ & $0.38^{a}$ & LB \\
\hline $\begin{array}{c}\text { AC Mon } \\
070100-0842.5^{a}\end{array}$ & $07005981-0842323$ & 0812-0117612 & 10.09 & 1.24 & $1885.6^{a}$ & $8.015^{a}$ & $0.64^{a}$ & DCEP \\
\hline $\begin{array}{c}\text { BB Mon } \\
070117-0841.7^{a}\end{array}$ & $07011648-0841425$ & 0813-0119156 & 10.55 & 0.18 & 4516.055 & 1.4654 & 0.62 & EA \\
\hline $\begin{array}{c}\text { EX Mon } \\
070159-0806.2^{a}\end{array}$ & 07015916-0806132 & 0818-0131510 & 11.87 & 1.78 & $2530.7^{a}$ & $135.6^{a}$ & $1.01^{a}$ & $\mathrm{LB}$ \\
\hline $070102-0811.5^{a}$ & 07010219-0811315 & 0818-0130620 & 12.09 & 1.61 & $1950.5^{a}$ & $28.59^{a}$ & $0.31^{a}$ & LB \\
\hline EW Mon & $07013057-0801111$ & 0819-0134879 & 13.25 & 0.65 & 4519.95 & 0.7647 & 0.42 & $\mathrm{~EB}$ \\
\hline
\end{tabular}

a: From ASAS.

표 2.- $\delta$ Scuti형 변광성의 주기분석 결과.

\begin{tabular}{ccccc}
\hline \hline No. & Value & Frequency $^{a, b}$ & Amp. $^{b, c}$ & S/N \\
\hline V3 & $f_{1}$ & 4.3831 & 0.027 & 18.0 \\
& $f_{2}$ & 8.7528 & 0.006 & 4.5 \\
V4 & $f_{1}$ & 25.1221 & 0.028 & 11.2 \\
& $f_{2}$ & 26.6254 & 0.012 & 4.9 \\
\hline
\end{tabular}

$a:$ In cycles per day.

${ }^{b}: V=$ Const $+\Sigma_{j} A_{j} \cos \left\{2 \pi f_{j}\left(t-t_{0}\right)+\phi_{j}\right\}$, $t_{0}=$ HJD 2,450,000.0

c: Total amplitude

연구에서 $\mathrm{ASAS}$ 에서 관측된 변광성보다 더 많은 변광 성이 발견되었다. 표 1 에서 $\mathrm{ASAS}$ 에서 관측된 변광성은 주기가 긴 변광성에 한정되어 있고, 변광진폭도 0.3 등급 보다 크다. 반면에 우리의 연구는 $\mathrm{V} 4$ 와 같이 아주 짧 은 주기의 변광성과 $\mathrm{V} 3$ 와 $\mathrm{V} 4$ 처럼 작은 진폭의 변광성 이 쉽게 찾아진다. 그리고 $\mathrm{ASAS}$ 의 결과로부터 이전의 SPVS 연구 (Jeon et al. 2007; Lee et al. 2007)에서도 많이 나타나는 변광형을 분류하기 어려운 변광성들이 비 주기성의 장주기형 변광성임을 확인할 수 있었다.

\section{1. $\delta$ Scuti형 변광성}

그림 2 는 2 개의 새로운 $\delta$ Scuti형 변광성에 대한 위상 맞추기 결과이다. 약 0.03 등급의 진폭으로 미세하게 변 하고 있다. 각각의 그림에서 위쪽은 $V$ 등급 광도곡선이

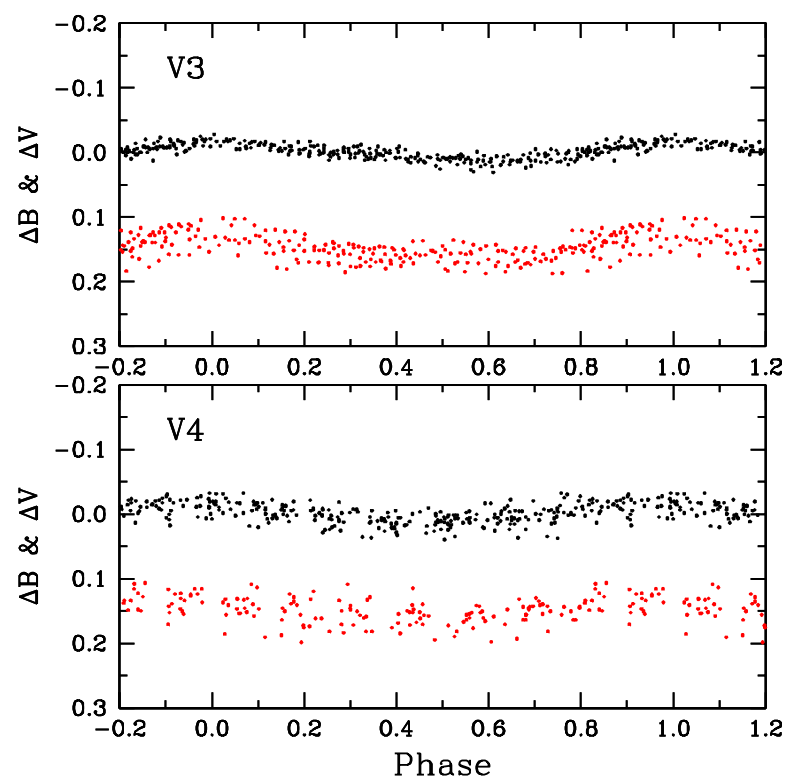

그림 2.- $\delta$ Scuti 형 변광성인 V3와 $\mathrm{V} 4$ 의 위상 맞추기 결과. 각각의 패널에서 위쪽은 $V$ 필터, 아래쪽은 $B$ 필터의 차등등급이며, $\Delta V$ 의 평균값을 0 으로 정규화하고, $\Delta B$ 는 $\Delta V$ 에 대해 일정한 값( 0.15 등급)만큼 차이가 나도록 하였 다. 

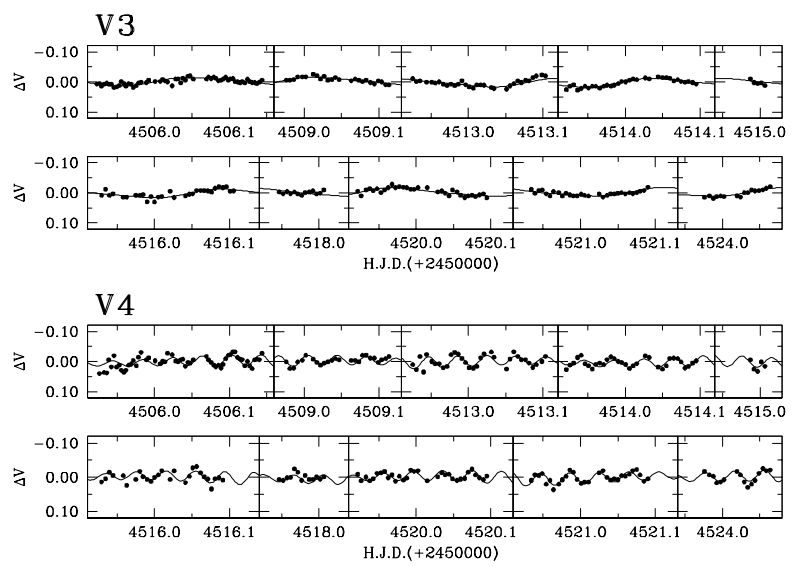

그림 3. $-\delta$ Scuti형 변광성의 광도곡선. 검은 점은 $V$ 필 터의 관측자료이며, 실선은 주기분석의 결과를 중첩한 것 이다.
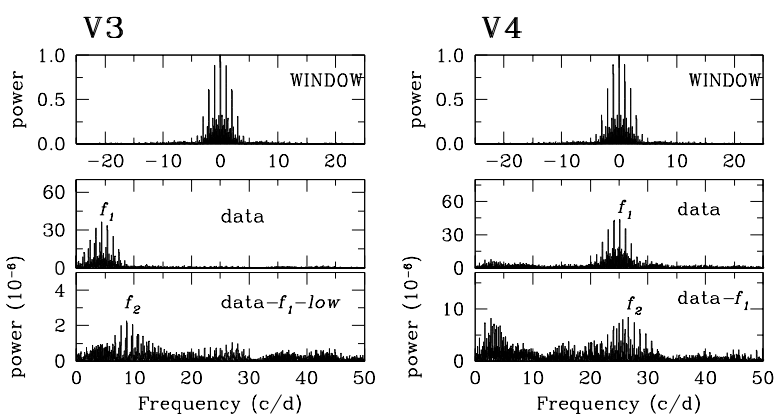

그림 4. $-\delta$ Scuti형 변광성의 파워 스펙트럼.

며, 아래쪽은 $B$ 등급 결과이다. 관측과정에서 $B$ 필터와 와 $V$ 필터에 대해 같은 노출시간을 적용하여 $B$ 등급의 측광 오차가 $V$ 등급 보다 더 크며, $B$ 등급 광도곡선의 분산이 크게 나타났다. $\mathrm{V} 3$ 의 경우 이러한 필터간 광도 곡선의 분산 차이를 고려하여도 $B$ 등급의 변광진폭이 약 0.05 로서 $V$ 등급의 변광진폭 0.033 보다 크게 나타나는데 이것은 맥동 변광성의 특징이다 (Jin et al. 2004).

그림 3 은 2 개의 $\delta$ Scuti형 변광성에 대해 이산 푸리 에 변환(Discrete Fourier Transform)과 다중회귀에 의 한 주기 분석 $(\mathrm{Kim} \&$ Lee 1995)을 수행한 결과이다. 그 림 3 에서 관측결과는 점으로 나타내었고 주기분석의 결 과는 실선으로 중첩하여 나타내었다. 그림 4 는 이들의 파워 스펙트럼을 보인 것이다.

주기 분석의 결과는 표 2 에 정리하였다. 표 2 에서 주 파수는 Breger et al. (1993)에 의해 제안된 신호대 잡음 비 $(S / N) \geq 4.0$ 인 것을 택하였다. 비록 소형망원경이 가지는 관측적인 한계로 인하여 각 변광성의 정확한 주 기를 모두 찾아내기는 어렵지만 그림 2 , 그림 3 및 그림 4 로부터 2 개 모두 $\delta \mathrm{Scuti}$ 형 변광성의 특징을 잘 보여주 고 있다. 또한 그림 5 의 색-등급도로부터 두 별 모두 불

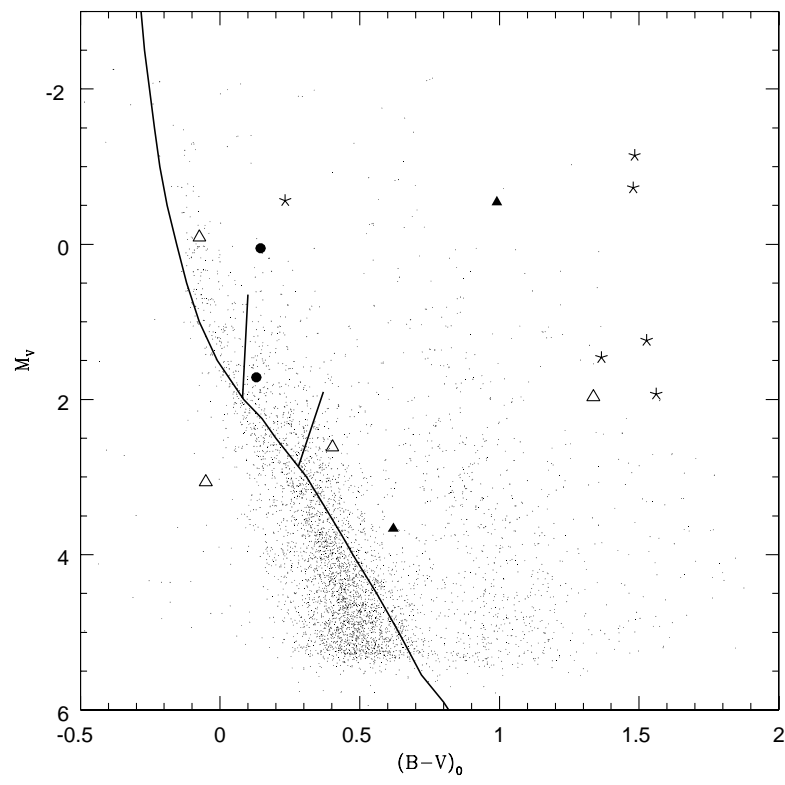

그림 5.- 관측된 영역의 색-등급도. 검은원은 $\delta \mathrm{Scuti}$ 를, 빈삼각형은 식쌍성을 나타낸 것이며, 위쪽 검은삼각형은 Cepheid 변광성인 $\mathrm{AC} \mathrm{Mon}$ 이며, 아래 검은삼각형은 $\mathrm{RR}$ Lyrae 형으로 분류한 V8이다. 나머지 별모양은 긴주기로 변광하거나 분류가 어려운 별들이다. $B$ 와 $V$ 등급은 관 측된 기기등급을 Clariá et al. (1998)의 결과로 표준화한 것이다. 영연령주계열(ZAMS)과 $\delta \mathrm{Scuti}$ 불안정대는 각각 Sung \& Bessell (1999)와 Breger (1979)의 경험적 결과이 다.

안정대의 가장자리에 위치하고 있으나 보다 밝은 $\mathrm{V} 3$ 는 $\mathrm{M} 50$ 에 속한 별로 보기는 어렵겠으나 V4는 M50의 별로 보여진다.

그림 5의 색-등급도는 Clariá et al. (1998)의 광전 관측에 의한 결과를 이용하여 표준화한 것이며, 사용 된 영연령주계열 $(\mathrm{ZAMS})$ 과 $\delta \mathrm{Scuti}$ 불안정대는 각각 Sung \& Bessell (1999)와 Breger (1979)의 결과이다. 여기에 적용된 거리지수와 성간소광량은 각각 $(m-$ $\left.M_{V}\right)_{0}=9.86$ 과 $E(B-V)=0.25$ (Clariá et al. 1998)이 다.

\section{2. 식변광성}

그림 6 은 표 1 에 정리된 식변광성들의 위상맞추기 결과 를 나타낸 것이다. 이들의 주기와 진폭 등의 물리량은 표 1 에 수록되었다. 새로운 변광성 $\mathrm{V} 6$ 과 $\mathrm{V} 7$ 은 각각 $\mathrm{W}$ $\mathrm{UMa}(\mathrm{EW})$ 형과 Algol $(\mathrm{EA})$ 형 식쌍성이며, 알려진 식 쌍성 중에서 $\mathrm{BB} \mathrm{Mon}$ 은 $\mathrm{ASAS}$ 에 관측되어 있으나 $\mathrm{EW}$ Mon은 ASAS 목록에 빠져 있다. EW Mon은 GCVS에 $\mathrm{EB}$ 형으로 분류되어 있으며 그림 1 에서 주변별과 잘 분 리되어 있고, 그림 6 에서 잘 정의된 광도곡선을 보여주 


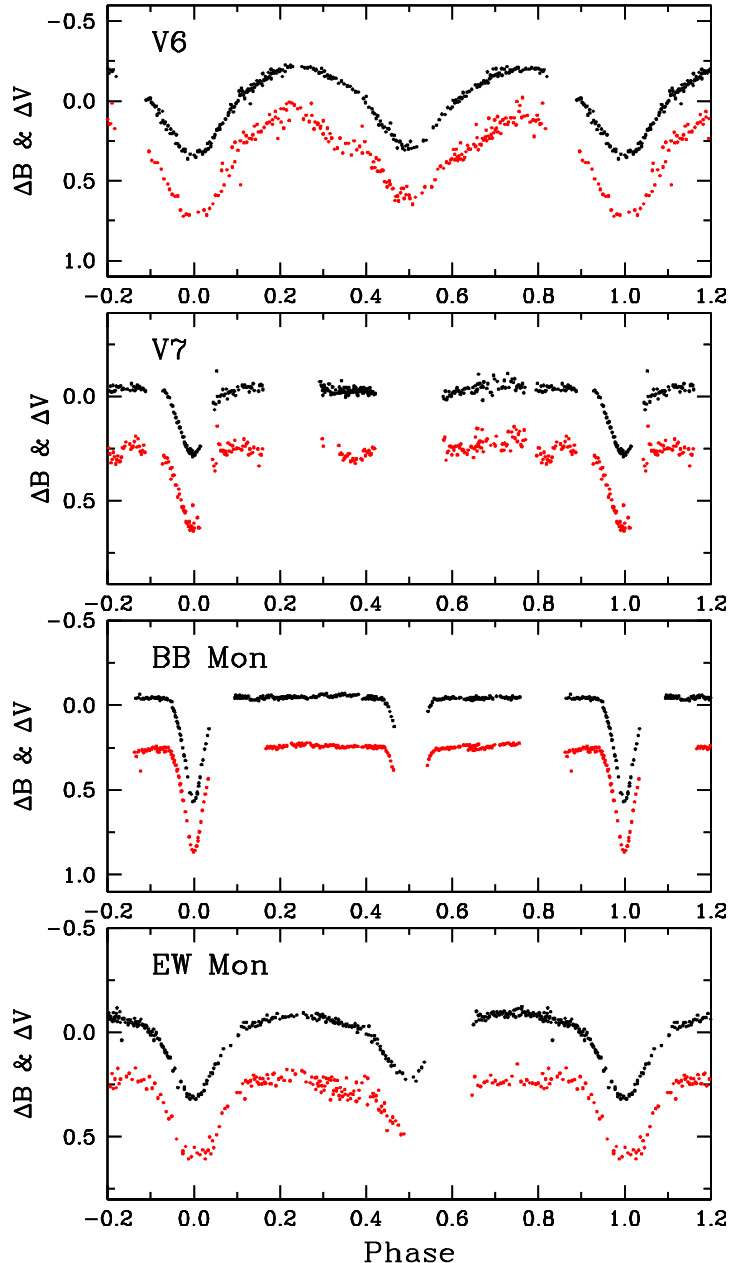

그림 6.- 식 변광성의 위상맞추기 결과. 각 패널의 설명 은 그림 2 와 같다.

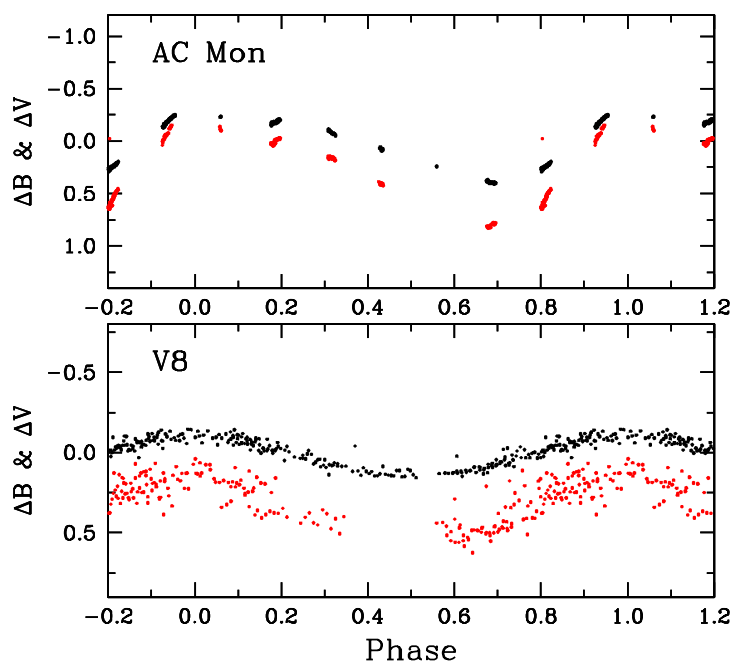

그림 7.- Cepheid 변광성 (AC Mon)과 RR Lyrae 변광성 으로 추정되는 별 $(\mathrm{V} 8)$. 각 패널의 설명은 그림 2 와 같다.

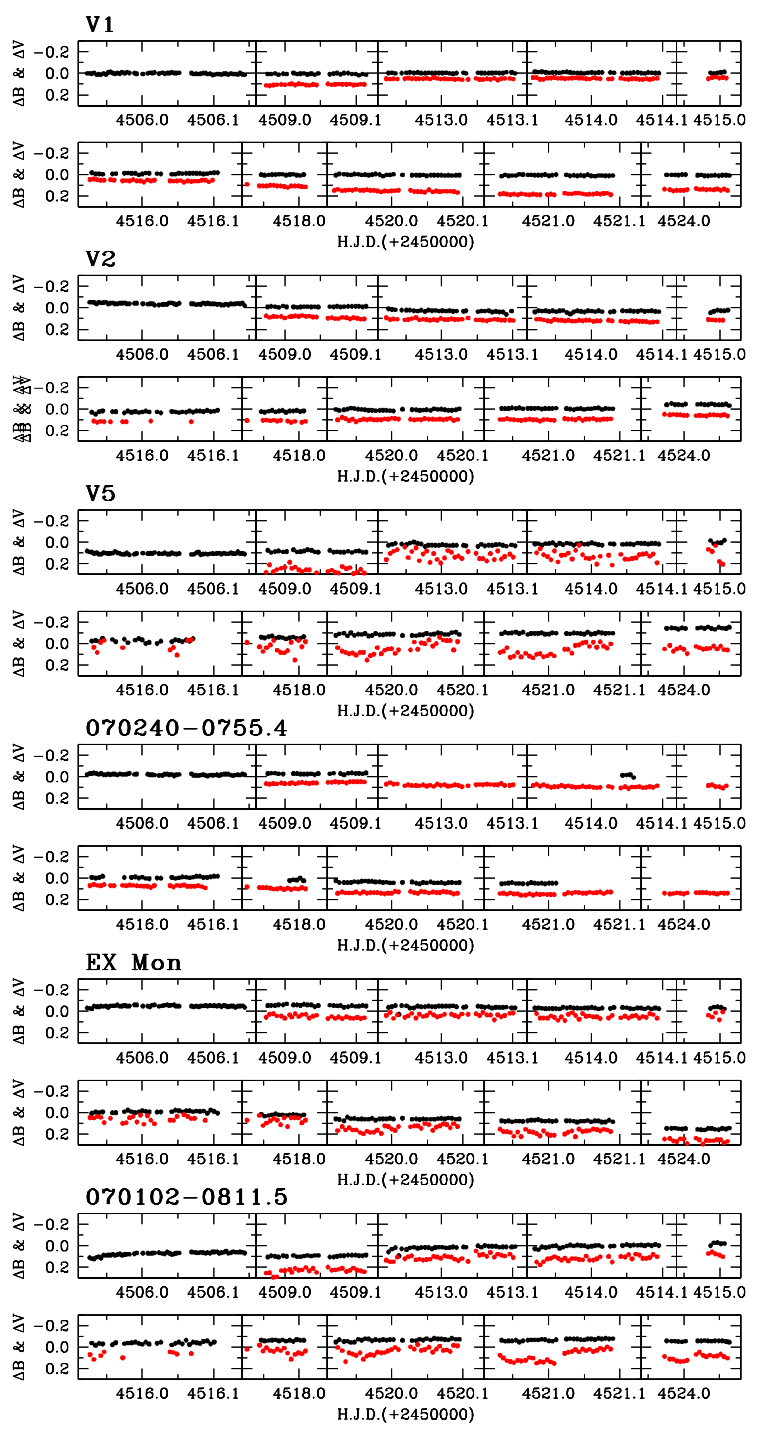

그림 8.- 변광성 분류 및 주기 결정이 안되는 변광성. 각 패널의 설명은 그림 2 와 같다.

고 있다.

\section{3. 기타}

그림 7에서 $\mathrm{AC} \mathrm{Mon은} \delta$ Cepheid 형이며, $\mathrm{ASAS}$ 의 주기 8.015 일을 적용하였다. $\mathrm{V} 8$ 은 $B$ 등급과 $V$ 등급의 변광진 폭이 서로 차이가 보이는 점에서 맥동 변광성으로 보고, 주기로 미루어 RR Lyrae 형으로 분류하였다. 하지만 이 별은 주기가 0.509 일로서 하나의 관측지에서 하루 단 위로 관측하여 전체 위상을 얻기가 아주 어려운 대상이 다. 따라서 2 년이상 시간 간격을 두고 관측하거나 시간 차이가 나는 다른 천문대와 다중 사이트 (multi-site) 관 측이 필요한 대상이다. 


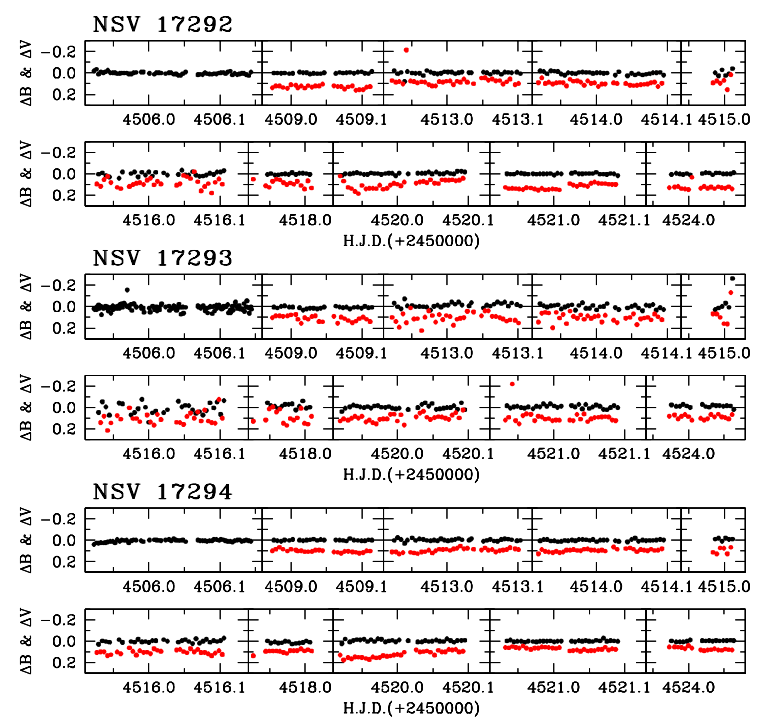

그림 9.- GCVS에서 변광성으로 분류된 별들. 세 별 모 두 변광성이 아니다. 각 패널의 설명은 그림 2 와 같다.

변광성 분류 및 주기 결정이 어려운 변광성의 광도곡 선을 그림 8 에 모았다. $\mathrm{V} 1$ 은 $B$ 등급 자료에서 횔씬 큰 변광을 보이고 있다. V5, EX Mon 및 070102-0811.5의 $B$ 등급 자료에서 분산이 큰 것은 어두워서 측광오차가 크기 때문이고, 070240-0755.4의 $V$ 등급에서 관측자료 가 비어있는 부분은 변광성이 밝아서 시상이 좋은날 관 측 자료가 포화되어 잃어버린 것이다. 그림 8 에 수록된 변광성들은 모두 약 18 일의 관측기간에 지속적으로 변 화하는 모습을 보이고 있다. V1을 제외한 나머지 5 개의 변광성이 모두 만기형이며, 이들 변광성은 $\mathrm{ASAS}$ 의 관 측 자료에서 보면 특별한 주기성이 없이 지속적으로 변 광하고 있는 모습을 나타내고 있다.

그림 9 의 세 별은 GCVS에서 변광폭이 0.1 등급 정도 인 변광성으로 분류되었으나 이번 연구의 광도곡선을 보 면 변광하지 않는 것으로 판단된다. 특히 NSV 17293은 바로 옆에 별이 붙어 있어서 시상 변화에 따라 측광 등 급의 오차가 크게 나타났다.

\section{4. 요약 및 검토}

보현산천문대의 단주기변광성 탐사연구(SPVS)의 일환 으로 M50 영역에서 14 개의 변광성을 찾았는데 그 중에 서 6 개는 알려진 변광성이며, 8 개는 새로운 변광성이었 다. 특히 이 영역은 $\mathrm{ASAS}$ 의 관측 영역에 속하여 알려 진 6 개 중에서 5 개는 $\mathrm{ASAS}$ 에 목록화된 변광성이었다. 새로 발견된 변광성은 대체로 주기가 짧거나 변광진폭이 작은 것들이었으며 SPVS연구가 $\mathrm{ASAS}$ 와 차별화 될 수 있음을 보여 주었다.

Kalirai et al. (2003)에서 산개성단 M50의 $\delta$ Scuti 불 안정대에 대략적으로 속하는 $V \sim 12-14$ 등급대의 별
은 약 100 여개인데 이번 연구에서는 단지 2 개의 $\delta$ Scuti 형 변광성을 찾았다. 그 중에서도 1 개는 성단에 속하지 않은 별로 보이므로 단지 1 개만 발견한 셈이다. $\delta$ Scuti 형 변광성은 변광진폭이 0.02 등급 이하로 극히 작은 경 우가 가장 많은 빈도를 차지하고 있어서 (Breger 1979) 이번 관측으로 발견하지 못한 $\delta \mathrm{Scuti}$ 형 변광성이 더 존 재할 가능성이 크겠다.

\section{참고문헌}

Breger, M., 1979, Delta Scuti \& Related Stars, PASP, 91,5

Breger, M., Stich, J., Garrido, R., et al., 1993, Nonradial Pulsation of the Delta-Scuti Star Bu-Cancri in the Praesepe Cluster, A\&Ap, 271, 482

Clariá, J. J., Piatti, A. E., \& Lapasset, E., 1998, Photometric study of the open cluster NGC 2323, A\& Ap Suppl., 127, 2436

Jeon, Y.-B., Nam, K.-H., Kim, S.-L., et al., 2004a, A New Field $\delta$ Scuti Star : HD 235428, PKAS, 19, 27

Jeon, Y.-B., Nam, K.-H., Park, Y.-H., et al., 2004b, A New Field $\delta$ Scuti Star : GSC 03665-00576, PKAS, 19, 33

Jeon, Y.-B., Nam, K.-H., Park, Y.-H., et al., 2007, Preliminary Results for Short-Period Variability Survey (SPVS): New Field Variable Stars, PKAS, 22,141

Jeon, Y.-B., Kim, S.-L., Park, Y.-H., et al., 2005a, Short-Period Variability Survey (SPVS) in BOAO, PKAS, 20, 21

Jeon, Y.-B., Park, Y.-H., Nam, K.-H., et al., 2005b, New Variable Stars around the Cepheid Variable TU Cas, PKAS, 20, 29

Jin, H., Kim, S.-L., Lee, C.-U., Lee, D.J., \& Kim, K.S., 2004, Reclassification of ROTSE-I $\delta$ Scuti type stars with Multiband photometry and Fourier Decomposition, AJ, 128, 1847

Kalirai, J. S., Fahlman, G. G., Richer, H. B., \& Ventura, P., 2003, THE CFHT Open Star Cluster Survey. IV. Two Rich, Young Open Star Clusters: NGC 2168 (M35) and NGC 2323 (M50), AJ, 126, 1402

Kim, S.-L. \& Lee, S.-W., 1995, CCD Photometry of a Delta Scuti Star in an Open Cluster II. BT CNC in the Praesepe, JKAS, 28, 197

Lee, E.-J., Jeon, Y.-B., Lee, H., \& Park, H.-S., 2007, A Search for New Variable Stars in the Open Cluster NGC 129 using a Small Telescop, JKAS, 28, 87

Massey, P. \& Davis, L. E., 1992, A User's Guide to Stellar CCD photometry with IRAF 
Pojmanski, G., Pilecki, B., \& Szczygiel, D., 2005, The All Sky Automated Survey. The Catalog of Variable Stars. V. Declinations $0 \mathrm{deg}-28 \mathrm{deg}$ of the Northern Hemisphere, Acta Astronomica, 55, 275

Rucinski, S. M., 2007, The short period end of the contact binary period distribution based on the All Sky Automated Survey (ASAS), MNRAS, 382, 393

Samus, N. N., Durlevich, O. V., et al., 2004, Combined General Catalogue of Variable Stars (Samus+2004), VizieR Online Data Catalog, 2250

Stetson, P. B., 1987, DAOPHOT - A computer program for crowded-field stellar photometry, PASP, 99, 191

Sung, H. \& Bessell, M. S., 1999, UBVI CCD photometry of M35 (NGC 2168), MNRAS, 306, 361-370. 